\title{
INDÚSTRIA PETROLÍFERA, MERCADO DE TRABALHO E NÍVEL \\ DE DEPENDÊNCIA DA MÃO DE OBRA EXÓGENA NOS MUNICÍPIOS PRODUTORES DE PETRÓLEO DA BACIA DE CAMPOS, RJ
}

\author{
Joseane De SOUZA \\ Denise Cunha Tavares Terra \\ Universidade Estadual do Norte Fluminense Darcy Ribeiro, Centro de Ciências do Homem, \\ Campos dos Goytacazes, RJ, Brasil
}

\begin{abstract}
R E S U M O : Os municipios produtores de petróleo da Bacia de Campos, no Rio de Janeiro, vêm apresentando significativas transformaçōes econômicas e sociais. Destaca-se a mudança na estrutura ocupacional, impulsionada pelas novas oportunidades de trabalho nos setores secundário e terciário, que tem atraido muitos imigrantes, além do crescimento do movimento pendular por motivo de trabalho. Este artigo tem como principal objetivo compreender essa nova dinâmica. Para tanto, foi desenvolvido um indicador para medir o nivel de dependência do mercado de trabalho de mão de obra exógena, admitida como sendo constituida por todos os trabalhadores imigrantes (não naturais e de data fixa), residentes em determinado municipio, e por trabalhadores pendulares. Os resultados apontam que o nivel de dependência de mão de obra exógena dos municípios analisados pode alcançar até cerca de 60\%, como é o caso de Macaé, onde se encontra a base de operaçôes da Petrobras e de outras empresas petroliferas.
\end{abstract}

P A L A V R A S - C H A V E : nivelde dependência; migraçâo; pendularidade; mercado de trabalho.

\section{INTRODUÇÃO}

Este artigo tem como principal objetivo desenvolver um indicador do nível de dependência de um mercado de trabalho de mão de obra exógena, constituída tanto por todos os trabalhadores imigrantes (não naturais e de data fixa) residentes em determinado município quanto por trabalhadores pendulares.

Para o desenvolvimento desse indicador, considerou-se um conjunto de 10 municípios, localizados no interior do estado do Rio de Janeiro: Armação dos Búzios, Arraial do Cabo, Cabo Frio e Rio das Ostras - na Baixada Litorânea; Campos dos Goytacazes, Carapebus, Casimiro de Abreu, Macaé, Quissamã e São João da Barra - no Norte Fluminense. Esses municípios são os principais produtores de petróleo da Bacia de Campos e muitos deles, notadamente aqueles do Norte Fluminense, destacavam-se 
na indústria sucroalcooleira até 1970, quando tal setor entrou em decadência. Nesse mesmo período, a Petrobras se instalou em Macaé, dando início às atividades de exploração e produção de petróleo e gás natural em 1974. O desenvolvimento desse novo setor industrial efetuou significativas mudanças estruturais na regiáo. Dentre elas, sobressai a mudança na estrutura ocupacional, com a redução relativa do emprego agrícola e aumento das oportunidades de trabalho nos setores secundário e terciário, impulsionado pelo próprio desenvolvimento do setor industrial.

Em decorrência disso, o mercado de trabalho tornou-se mais seletivo, exigindo maior qualificação dos trabalhadores. Segundo Souza, Terra e Campos (2012, p. 18), "apesar da possibilidade de transferência intersetorial da mão de obra, parte da oferta das vagas vem sendo ocupada por imigrantes - interestaduais, intraestaduais e internacionais - já que muitas vezes os naturais não apresentam nível de escolaridade suficiente para ocupá-las". Eles constataram, ainda, o incremento, entre 2000 e 2010, do número de trabalhadores pendulares, com significativas diferenças socioeconômicas dos sujeitos que compóem esses fluxos. Partindo-se dessas observaçóes e considerando-se a reestruturaçáo produtiva da região, assim como as especificidades dos regimes de contratação de seu mercado de trabalho, surge esta inquietação: em que medida esses mercados de trabalho dependem de mão de obra exógena?

Este artigo é composto, além da introdução e conclusão, por mais cinco partes. Inicialmente, discute-se a relação entre industrialização e movimentos migratórios, chamando a atençấo para o caso brasileiro, sobretudo para as mudanças nos padróes migratórios a partir dos anos 1980. Duas dessas mudanças se destacam do conjunto, dada a importância que representam para a discussão: o aumento dos movimentos pendulares e o processo de interiorização. Em seguida, aborda-se a relaçâo entre o desenvolvimento da indústria petrolífera e a nova dinâmica econômica e territorial no Rio de Janeiro, na tentativa de demonstrar que, embora a indústria petrolífera se concentre em Macaé, haja diferenças socioeconômicas entre os municípios e inexista uma força agregadora que os transforme em uma "aglomeração urbana", não deve ser menosprezada a intensa interação socioeconômica e demográfica que há entre eles. Apresentam-se, logo após, os resultados referentes aos movimentos migratórios e pendulares por motivo de trabalho, entre os municípios selecionados e outros municípios do Rio de Janeiro e de outras Unidades Federativas (UFs) brasileiras, para o quinquênio de 2005-2010. Busca-se, com isso, demonstrar a capacidade de atração que os municípios em questão exercem sobre os migrantes e indivíduos que residem em outras regiôes do país ou em diferentes municípios do Rio de Janeiro. Na parte subsequente, expóe-se a metodologia usada na estimativa do nível de dependência de mão de obra exógena em um mercado de trabalho e o detalhamento conceitual das variáveis nela envolvidas. Por último, encontram-se os resultados da aplicação dessa metodologia.

\section{BREVES CONSIDERAÇÕES SOBRE AS MUDANÇAS NOS PADRÕES MIGRATÓRIOS BRASILEIROS}

No caso brasileiro, a industrialização trouxe uma série de mudanças, como a redistribuição espacial da população, a reestruturação das classes sociais, com a constituição de uma classe média urbana, a reestruturação ocupacional, com o surgi- 
mento das novas ocupaçóes industriais e urbanas, e a expansão do setor de serviços (JANUZZI, 2000). Em relação às alteraçôes na redistribuição espacial da população brasileira, Brito (2002, p. 5) afirma que as "trajetórias migratórias são alimentadas pelos fortes desequilíbrios regionais e sociais" e que, ademais, constituem um "poderoso mecanismo de transferência espacial da população do 'excedente demográfico' de determinada regiáo, incapaz de absorvê-lo em sua economia e em sua sociedade", para outra, mais desenvolvida.

Sem entrar no mérito dos volumes, pode-se dizer que, no Brasil, os fluxos migratórios interestaduais e intraestaduais vêm, de fato, seguindo os caminhos da industrialização e da abertura das frentes de expansão agrícola. Nas décadas de 1940, 1950 e 1960, Sáo Paulo e Rio de Janeiro - os primeiros estados brasileiros a se industrializarem - destacaram-se, segundo Brito (2002), como as principais áreas de destino dos migrantes interestaduais. O Paraná e o Centro-Oeste - fronteiras agrícolas em expansão, caracterizadas por amplas "alternativas de acesso à terra, ao emprego ou à atividade mineral" (SAWYER, 1984 apud BRITO, 2002, p. 17) - também apareciam como importantes áreas de absorção da mão de obra emigrante. Já a regiáo Nordeste e o Estado de Minas Gerais eram as principais áreas de origem migratória.

Brito (2002) sublinha, ainda, a importância dos fluxos migratórios secundários - tanto intra quanto interestaduais, no caso de regióes fronteiriças - sob o ponto de vista da redistribuição espacial da população. $\mathrm{O}$ autor mostra que, embora em escala regional, as origens e os destinos dos migrantes obedeciam à mesma lógica anterior: as áreas menos desenvolvidas continuavam sendo zonas de origem e as mais desenvolvidas, notadamente as regióes metropolitanas, as zonas de destino.

É interessante observar que, à medida que as condiçôes socioeconômicas alteraramse e a atividade produtiva "desconcentrou-se", as características dos padróes migratórios também se modificaram. Em relação às mudanças nos padrôes migratórios, podem ser mencionados, conforme Brito (2002) e Oliveira (2011), os seguintes aspectos:

- Inversão das principais correntes migratórias no Estado do Rio de Janeiro, que, de receptor populacional líquido, até os anos 1980, passou a apresentar, a partir da década de 1990, saldo migratório negativo, e de Minas Gerais, que, de fornecedor de mão de obra, se tornou receptor líquido de população nos anos 1990;

- Redução da atratividade populacional exercida por São Paulo;

- Aumento da retenção e atração populacional na Região Nordeste;

- Inversão do saldo migratório do Paraná, que, de positivo e elevado, em 1970, passou a negativo e elevado, em 1980, refletindo o esgotamento da fronteira agrícola;

- Aumento da circulação migratória entre o Centro-Oeste e a região Norte, bem como dos movimentos migratórios no interior das respectivas fronteiras agrícolas, indicando o processo de esgotamento delas;

- Elevação da migração de retorno, principalmente para a região Nordeste e Minas Gerais;

- Intensificação dos movimentos pendulares;

- Surgimento de eixos de deslocamentos populacionais em direção a regióes interioranas.

Considerando-se o objetivo deste artigo, dentre as mudanças acima mencionadas, as duas últimas têm particular importância, uma vez que tanto os movimentos 
migratórios quanto os pendulares são percebidos como estratégias fundamentais para suprir a escassez - relativa ou absoluta - de mão de obra no mercado de trabalho.

\section{INDÚSTRIA PETROLÍFERA E A NOVA DINÂMICA ECONÔMICA E TERRITORIAL NO RIO DE JANEIRO}

Simôes e Amaral (2011) sustentam que tem ocorrido no Brasil, principalmente a partir do início dos anos 1980, um processo de interiorização - marcado por uma "desconcentração-concentrada" - da atividade econômica, cuja consequência é o surgimento de novas centralidade urbanas. Segundo Baeninger (2004), esse processo relaciona-se a estes fatores: crise econômica dos anos 1980; melhor desempenho da agricultura e das atividades de exploração mineral; crescimento e urbanização das áreas de fronteira; desenvolvimento da agroindústria. No entanto, a intensificação observada nas duas últimas décadas deve-se aos incentivos fiscais concedidos, em especial, pelos governos estaduais, associados a fatores locacionais, como as deseconomias de aglomeração e as economias de escala (SIMÓES; AMARAL, 2011, p. 554).

É importante ressaltar que, por um lado, a desconcentração da atividade industrial - logo, a desconcentração relativa das oportunidades de emprego - e o surgimento de novas centralidades urbanas criam novas áreas de atraçáo populacional no interior do país. Por outro, o maior acesso à informação e, em consequência, o aumento do conhecimento sobre os problemas nos grandes centros urbanos (preços do mercado imobiliário, dificuldades de empregabilidade, precariedade da infraestrutura urbana, escassez relativa de serviços urbanos, segregação socioespacial da população, dentre outros) e nas fronteiras agrícolas (rígida estrutura fundiária, dificuldade de acesso à terra, precarização dos empregos, dentre outros) têm influenciado a redução do poder de atração e retenção populacional nessas áreas e a escolha da regiáo de destino pelos migrantes (BRITO, 2002, p. 41).

A indústria petrolífera, por exemplo, tem gerado novas polarizaçôes demográficas e produzido significativas alteraçôes na espacialização da riqueza no Rio de Janeiro. Isso decorre de seus crescentes investimentos na atividade de exploração, desenvolvimento e produção de petróleo e gás (segmento denominado upstream) e das elevadas compensaçóes financeiras pagas aos municípios considerados "produtores de petróleo" (confrontantes com os poços offshore em operação). Tais fatores foram alguns dos que mais contribuíram para que a Região Metropolitana do Rio de Janeiro, apesar da excessiva polarização em termos econômicos e populacionais, iniciasse um processo de redução do seu peso na economia fluminense.

A Tabela 1 mostra que o crescimento médio anual da populaçáo da Região Metropolitana foi, na última década, inferior à média estadual e significativamente inferior às taxas de crescimento observadas nas Regióes das Baixadas Litorâneas, que apresentou o maior crescimento médio anual $(3,8 \%)$, da Costa Verde $(3,4 \%)$ e do Norte Fluminense (2,0\%). 
Tabela 1: Rio de Janeiro e Regióes de Governo - Taxa Média anual de crescimento populacional, por Regiôes de Governo do Estado do Rio de Janeiro, 1991-2010

\begin{tabular}{l|c|c}
\hline \multirow{2}{*}{ Estado e Regiōes de Governo } & \multicolumn{2}{|c}{ Taxa média anual de crescimento (\%) } \\
\cline { 2 - 3 } & $1991-2000$ & $2000-2010$ \\
\hline Estado do Rio de Janeiro & 1,3 & 1,1 \\
\hline Regiāo Metropolitana & 1,2 & 0,9 \\
\hline Regiāo Norte Fluminense & 1,5 & 2,0 \\
\hline Regiāo Noroeste Fluminense & 1,0 & 0,6 \\
\hline Regiāo Serrana & 1,0 & 0,7 \\
\hline Região da Baixadas Litorâneas & 4,1 & 3,8 \\
\hline Regiāo do Médio Paraíba & 1,4 & 0,9 \\
\hline Regiāo Centro-Sul Fluminense & 1,2 & 0,7 \\
\hline Regiāo da Costa Verde & 3,5 & 3,4 \\
\hline
\end{tabular}

Fonte: IBGE - Censo Demográfico de 2000 e 2010.

Quanto à participação no Produto Interno Bruto estadual, a Região Metropolitana, conquanto tenha mantido uma alta concentração em termos de produto e respondido praticamente por toda a economia fluminense, perdeu posição, caindo de 76,49\% para 67,59\%, entre 2000 e 2010 . As Regióes das Baixadas Litorâneas e do Norte Fluminense distinguiram-se do restante, devido ao aumento, na última década, de suas participaçôes relativas na composição do PIB estadual, de 3,41\% e $6,49 \%$ para $5,25 \%$ e $11,21 \%$, respectivamente. Junto delas, também se encontra o Médio Paraíba, cujo índice se elevou de 6,61\% para 7,21\% (Tabela 2).

Tabela 2: Rio de Janeiro e Regiōes de Governo - Participação do Produto Interno Bruto nas Regiōes de Governo do Estado do Rio de Janeiro, 2000-2010

\begin{tabular}{l|c|c}
\hline \multirow{2}{*}{ Estado e Regiōes de Governo } & \multicolumn{2}{|c}{ PIB (\%) } \\
\cline { 2 - 3 } & 2000 & 2010 \\
\hline Estado do Rio de Janeiro & 100,00 & 100,0 \\
\hline Região Metropolitana & 76,49 & 67,6 \\
\hline Região Norte Fluminense & 6,49 & 11,2 \\
\hline Região Noroeste Fluminense & 1,11 & 0,9 \\
\hline Região Serrana & 3,76 & 3,8 \\
\hline Região da Baixadas Litorâneas & 3,41 & 5,3 \\
\hline Região do Médio Paraíba & 6,61 & 7,2 \\
\hline Região Centro-Sul Fluminense & 1,11 & 1,1 \\
\hline Região da Costa Verde & 1,03 & 2,9 \\
\hline
\end{tabular}

Fonte: Fundação CEPERJ, IBGE.

Nas Baixadas Litorâneas e no Norte Fluminense, há um conjunto de dez municípios, com diferentes formações socioeconômicas, que, apesar de pertencerem a distintas regióes político-administrativas, possuem uma identidade em comum: são considerados "produtores de petróleo" por força de lei, e, por adesão, beneficiários das compensaçôes financeiras advindas da atividade petrolífera. São eles: Armação dos Búzios, Arraial do Cabo e Cabo Frio, nas Baixadas Litorâneas; Campos dos Goytacazes, Carapebus, Casimiro de Abreu, Macaé, Quissamã, Rio das Ostras e São João da Barra, no Norte Fluminense (Figura 1). 
Em meados da década de 1970, a Petrobras implantou sua base operacional na cidade de Macaé. Isso resultou na instalação de um significativo número de empresas prestadoras de serviço, remodelando tanto as hierarquias urbanas quanto a paisagem econômica regional, até então historicamente baseada na produção de cana-deaçúcar e na pecuária bovina, já em declínio naquela ocasião. A partir de 1997, com a chamada Lei do Petróleo, que acabou com o monopólio da Petrobras na exploração e produção de petróleo e gás e aumentou a alíquota dos royalties de 5\% para 10\%, foram ampliados os investimentos na regiấo. Novas petroleiras passaram a operar diretamente na produçáo offshore, bem como houve um crescimento nos recursos das compensaçóes financeiras, o que provocou rápidas e radicais transformaçôes na organização desse território. Tudo isso trouxe mudanças na dinâmica populacional, no emprego, na densidade urbana, na política e na cultura, em dependência, é claro, do grau de inserção de cada município na economia regional (TERRA, 2003).

Figura 1: Municípios Selecionados do Estado do Rio de Janeiro

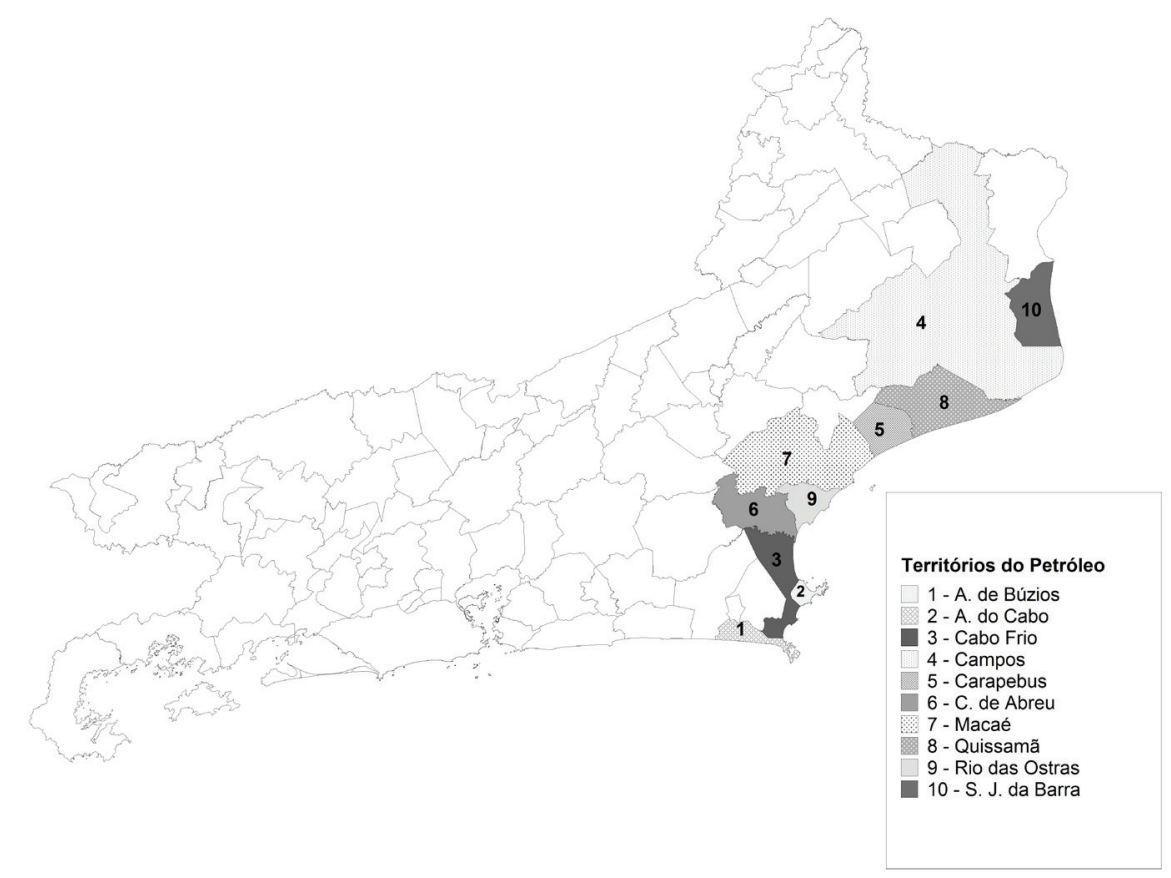

Fonte: organizado pelas autoras.

Em 2001, preocupados com a possibilidade de mudanças nas regras de rateio das rendas petrolíferas, os municípios localizados na chamada zona de produção principal - os maiores beneficiários desses recursos - decidiram criar a Organizaçấo dos Municípios Produtores de Petróleo e Gás da Bacia de Campos (OMPETRO). No momento de sua fundação, a organização compunha-se de nove municípios, sendo cinco do Norte Fluminense (Campos dos Goytacazes, São João da Barra, Macaé, Quissamã e Carapebus) e quatro das Baixadas Litorâneas (Armação de Búzios, Cabo Frio, Casimiro de Abreu e Rio das Ostras). Atualmente, mais dois municípios fazem parte dela: Niterói e Arraial do Cabo. Dentre os municípios da OMPETRO, o único não selecionado para este estudo foi Niterói, por dois motivos: (1) ele faz parte da Região Metropolitana do Rio de Janeiro (RMRJ), tendo sua dinâmica demográfica e 
socioeconômica determinada - e determinante - por aquela da zona metropolitana; (2) é espacialmente distante e não contíguo aos demais municípios selecionados.

$\mathrm{O}$ esforço de manter as atuais regras de repartição das rendas petrolíferas ocorre devido à extrema dependência dos municípios às receitas, como pode ser visto na Tabela 3. Enquanto os municípios da OMPETRO apresentam uma dependência média de recursos de aproximadamente $45 \%$, a de outros municípios do Rio de Janeiro fica em torno de 10\%. Sáo João da Barra, Campos dos Goytacazes e Rio das Ostras extrapolam a média da OMPETRO, alcançando 65,05\%, 56,32\% e 48,82\%, respectivamente.

Tabela 3: OMPETRO - Nível de dependência em relação às rendas petrolíferas, segundo o município, 2012

\begin{tabular}{l|r|r|r}
\hline Municípios da OMPETRO $^{[1]}$ & $\begin{array}{c}\text { Royalties e participaçôes } \\
\text { especiais }\end{array}$ & Receita Total & \multicolumn{1}{|c}{$\begin{array}{c}\text { Nível de } \\
\text { Dependência }\end{array}$} \\
\hline Armaçáo de Búzios & $81.291,10$ & $192.690,90$ & 42,19 \\
\hline Cabo Frio & $317.021,90$ & $723.130,60$ & 43,84 \\
\hline Carapebus & $39.017,30$ & $89.106,10$ & 43,79 \\
\hline Campos dos Goytacazes & $1.343 .756,70$ & $2.386 .097,80$ & 56,32 \\
\hline Casimiro de Abreu & $122.800,40$ & $277.904,20$ & 44,19 \\
\hline Macaé & $542.608,10$ & $1.912 .612,00$ & 28,37 \\
\hline Quissamá & $106.975,80$ & $242.225,60$ & 44,16 \\
\hline Rio das Ostras & $351.071,10$ & $719.108,90$ & 48,82 \\
\hline Sáo Joáo da Barra & $232.183,20$ & $356.929,40$ & 65,05 \\
\hline Ompetro & $3.136 .725,60$ & $6.899 .805,50$ & 45,46 \\
\hline Municípios do Estado do Rio de Janeiro & $4.474 .584,50$ & $40.974 .393,20$ & 10,92 \\
\hline
\end{tabular}

Fonte: Finanças dos Municípios Fluminenses, 2013.

${ }^{[1]}$ Municípios da OMPETRO no momento de sua criação.

${ }^{[2]} \mathrm{Em} \mathrm{R}$ \$ mil - IPCA médio de 2012.

Com o descobrimento de significativas reservas de pré-sal na Bacia de Campos, a importância da atividade petrolífera alongou-se para essa regiấo. Os investimentos previstos para o segmento de Petróleo e Gás, de 2012 a 2015, são de R 354 bilhôes, representando $59 \%$ das perspectivas de investimento da indústria brasileira no período (PERSPECTIVAS, 2012).

É possível afirmar, com base nos levantamentos, que investimentos de grande magnitude serão, provavelmente, um fator alimentador da dinâmica (já existente) de redistribuição espacial da população em direção à Bacia de Campos, onde grandes jazidas de petróleo e gás foram identificadas na área do pré-sal. Segundo distintas escalas geográficas, diferentes tipos de fluxos sustentam tal dinâmica. 


\section{AS MIGRAÇÕES E A MOBILIDADE PENDULAR NO CONTEXTO DOS MUNICÍPIOS SELECIONADOS}

Entre 2000 e 2010, em todos os municípios selecionados, a taxa de crescimento populacional médio anual foi superior ao ritmo médio estadual ( $1,1 \%$ ao ano) e metropolitano ( $0,9 \%$ ao ano). Dentre os municípios de crescimento mais acelerado, destacam-se Rio das Ostras (11,24\%aa), Casimiro de Abreu (4,78\%aa), Macaé (4,55\%aa), Carapebus (4,42\%aa) e Quissamã (4\%aa), localizados na microrregião de Macaé, no Norte Fluminense; Armação de Búzios (4,23\%aa) e Cabo Frio (3,92\%aa), na Baixada Litorânea.

No caso do Norte Fluminense, o acelerado crescimento populacional de Macaé é incitado pelo próprio dinamismo econômico do município, que, sendo base da indústria da exploração e produção de petróleo e gás, torna-se um importante destino para muitos migrantes internos. Em relação aos demais municípios, pode-se dizer que o crescimento populacional deles é provocado pelos efeitos das movimentaçóes econômicas de Macaé, pelo comportamento de seus respectivos mercados imobiliários, com ofertas de terras relativamente mais baratas, se comparadas ao preço da terra em Macaé, e pela proximidade espacial em relação a este último, a qual permite a realização de movimentos pendulares de distância e tempo relativamente curtos.

No caso de Búzios e Cabo Frio, na Baixada Litorânea, "o turismo e as atividades correlatas são responsáveis pela transformação radical da estrutura produtiva local, outrora dominada pela indústria salineira e pela pesca" (MONIÉ, 2003, p. 257).

Dentre os municípios selecionados, apenas três (Arraial do Cabo, Campos dos Goytacazes e São João da Barra) exibiram taxas de crescimento inferiores a 2\%. Com exceção de Cabo Frio, em todos os outros, o ritmo de crescimento apresentou-se bastante acelerado, com índices igual ou superior a $4 \%$ ao ano (Tabela 4).

Tabela 4: Municípios Selecionados - População e Taxa de Crescimento, 2000-2010

\begin{tabular}{l|r|r|c}
\hline \multirow{2}{*}{ Municípios Selecionados } & \multicolumn{2}{|c|}{ População } & \multirow{2}{*}{ Taxa de crescimento } \\
\cline { 2 - 3 } & \multicolumn{1}{c|}{2000} & \multicolumn{1}{c}{2010} & $(2000-2010)$ \\
\hline Armação de Búzios & 18.204 & \multicolumn{1}{c}{27.560} & 4,23 \\
\hline Arraial do Cabo & 23.877 & 27.715 & 1,50 \\
\hline Cabo Frio & 126.828 & 186.227 & 3,92 \\
\hline Carapebus & 8.666 & 13.359 & 4,42 \\
\hline Campos dos Goytacazes & 407.168 & 463.731 & 1,31 \\
\hline Casimiro de Abreu & 22.152 & 35.347 & 4,78 \\
\hline Macaé & 132.461 & 206.728 & 4,55 \\
\hline Quissamá & 13.674 & 20.242 & 4,00 \\
\hline Rio das Ostras & 36.419 & 105.676 & 11,24 \\
\hline São João da Barra & 27.682 & 32.747 & 1,69 \\
\hline Total & 817.131 & 1.119 .332 & 3,20 \\
\hline
\end{tabular}

Fonte: IBGE - Censo Demográfico de 2000 e 2010.

Sem dúvida, ritmos tâo acelerados de crescimento estão associados a intensos movimentos migratórios, os quais envolvem, necessariamente, uma mudança de residência. Pelo Censo Demográfico, é possível analisar os movimentos migratórios 
de última etapa - resultante da combinação das informaçôes referentes ao último lugar de residência e ao tempo (ininterrupto) de residência, colhidas com todos os indivíduos com menos de 10 anos de residência - e os de data fixa, que levam em conta apenas as mudanças de residência ocorridas entre duas divisóes político-administrativas em dois momentos distintos e fixos no tempo.

Independentemente de serem compreendidos como migração de última etapa ou de data fixa, os verdadeiros fluxos migratórios são desconhecidos, sendo identificados, em cada Censo, apenas os imigrantes sobreviventes ao duplo decremento (mortalidade e reemigração). Em outras palavras, trata-se sempre de uma estimativa, sujeita não apenas às diferenças conceituais, como também aos recortes adotados para sua classificação - questáo ressaltada por Carvalho e Rigotti (1998) e analisada em detalhes por Golgher (2006). Neste artigo, são levados em conta os movimentos migratórios entre duas datas fixas. Por esse critério, é considerado imigrante o indivíduo que não residia na população estudada no início do período de referência (1\%/Julho/2005), tendo-a declarado como residência no final do período (1\% Julho/2010). Uma limitação que se impóe com a adoção desse conceito é o fato de ela não contemplar os movimentos ocorridos no período entre a realização do Censo e a data fixa.

Pelas informações referentes às trocas populacionais entre os municípios pesquisados e outros estados brasileiros entre 2005 e 2010, observa-se que, em todos eles, os saldos migratórios interestaduais mostraram-se positivos, o que permite classificá-los como receptores líquidos de população residente em outras unidades da federação. Em conjunto, eles receberam 31.730 imigrantes interestaduais e deles emigraram um total de 11.407 indivíduos, resultando em um saldo migratório agregado de 20.323 pessoas (Tabela 5).

Tabela 5: Municípios Selecionados - Indicadores da Migração Interestadual, Intraestadual e Total, segundo o município selecionado, 2005-2010

\begin{tabular}{|c|c|c|c|c|c|c|c|c|c|c|c|c|}
\hline \multirow{2}{*}{$\begin{array}{l}\text { Municípios } \\
\text { Selecionados }\end{array}$} & \multicolumn{4}{|c|}{ Migraçâo Interesdual } & \multicolumn{4}{|c|}{ Migração Intraestadual } & \multicolumn{4}{|c|}{ Migração Total } \\
\hline & I & E & SM & TLM & I & E & SM & TLM & I & E & SM & TLM \\
\hline & 1.020 & 624 & 396 & 1,44 & 4.279 & 2.586 & 1.693 & 6,14 & 5.299 & 3.210 & 2.089 & 7,58 \\
\hline & 466 & 385 & 81 & 0,29 & 3.984 & 2.179 & 1.805 & 6,51 & 4.450 & 2.564 & 1.886 & 6,81 \\
\hline Cabo Frio & 4.803 & 2.436 & 2.367 & 1,27 & 30.301 & 17.073 & 13.228 & 7,10 & 35.104 & 19.509 & 15.595 & 8,37 \\
\hline Carapebus & 261 & 59 & 203 & 1,52 & 2.028 & 676 & 1.352 & 10,12 & 2.289 & 734 & 1.555 & 11,64 \\
\hline & 4.639 & 3.415 & 1.225 & 0,26 & 12.964 & 19.863 & -6.899 & $-1,49$ & 17.603 & 23.277 & -5.674 & $-1,22$ \\
\hline $\begin{array}{l}\text { Casimiro } \\
\text { de Abreu }\end{array}$ & 965 & 148 & 817 & 2,31 & 6.630 & 2.351 & 4.278 & 12,10 & 7.595 & 2.500 & 5.095 & 14,42 \\
\hline Macaé & 12.701 & 3.262 & 9.439 & 4,57 & 23.888 & 18.095 & 5.793 & 2,80 & 36.589 & 21.357 & 15.232 & 7,37 \\
\hline Quissamã & 259 & 0 & 259 & 1,28 & 2.009 & 927 & 1.082 & 5,35 & 2.268 & 927 & 1.341 & 6,62 \\
\hline $\begin{array}{l}\text { Rio das } \\
\text { Ostras }\end{array}$ & 6.062 & 1.041 & 5.021 & 4,75 & 34.657 & 9.072 & 25.585 & 24,21 & 40.719 & 10.113 & 30.606 & 28,96 \\
\hline $\begin{array}{l}\text { São João } \\
\text { da Barra }\end{array}$ & 553 & 39 & 515 & 1,57 & 3.149 & 1.420 & 1.729 & 5,28 & 3.702 & 1.458 & 2.244 & 6,85 \\
\hline Total & 31.730 & 11.407 & 20.323 & 1,82 & 123.888 & 74.241 & 49.647 & 4,44 & 155.618 & 85.648 & 69.970 & 6,25 \\
\hline
\end{tabular}

Fonte: IBGE - Censo Demográfico de 2010. 
1 Sem entrar no mérito da estimativa dessa taxa, ela nos dá o impacto exercido pela migração sobre o ritmo de crescimento populacional. Em linhas gerais, quanto maior a TLM, maior o impacto das migrações sobre o ritmo de crescimento de uma população. No caso de Rio das Ostras, por exemplo, o ritmo de crescimento populacional é $29 \%$ superior àquele que seria verificado na ausência de movimentos migratórios de e para aquele município.
No âmbito das migraçóes interestaduais, sobressaem como áreas de atração populacional os municípios de Macaé e Campos dos Goytacazes, no Norte Fluminense, e Rio das Ostras, Cabo Frio e Armação dos Búzios, na Baixada Litorânea. No entanto, o baixo poder de retenção e/ou elevado poder de expulsão populacional deles amenizam o impacto dos movimentos migratórios interestaduais sobre seus respectivos ritmos de crescimento, dado pela Taxa Líquida de Migração (TLM) ${ }^{1}$.

As trocas populacionais entre esses municípios e outros do Rio de Janeiro são, em número, significativamente superior às migraçōes interestaduais. Nestas últimas, especificamente no período entre 2005 e 2010, incluindo-se os intercâmbios populacionais entre os municípios selecionados, detecta-se um total de 123.888 imigrantes e 74.241 emigrantes, logo um saldo migratório positivo de 49.647 indivíduos (Tabela 5). Apenas Campos dos Goytacazes possui saldo migratório negativo; para todos os outros, tal saldo é relativamente elevado e impacta, consideravelmente, os respectivos ritmos de crescimento populacional.

Analisando as colunas com os resultados consolidados das migraçôes intra e interestaduais no período 2005-2010 (Tabela 5), verifica-se que os movimentos migratórios são significativos. Em termos brutos, são 241.266 migrantes; já em termos líquidos, nota-se um ganho populacional de 69.970 pessoas em apenas cinco anos. Se se considera os movimentos intra e interestaduais, o impacto das migrações sobre o ritmo de crescimento populacional de Rio das Ostras, Casimiro de Abreu e Carapebus é da ordem de 29\%, 14,4\% e 11,6\%, respectivamente. Como as migraçôes intraestaduais são de maior magnitude, em Campos o efeito desses movimentos no ritmo de crescimento populacional é negativo, da ordem de $-1,2 \%$.

Em relação aos movimentos pendulares, Souza, Terra e Campos (2013) sugerem que, de 2000 para 2010, houve uma intensificação deles entre os municípios da OMPETRO. Os autores afirmam que a pendularidade por motivo de trabalho aumentou de 14.019 trabalhadores, em 2000, para 43.642, em 2010. Uma vez que a pendularidade e as migraçóes são altamente seletivas pelo critério da idade, é importante examinar não apenas sua variação absoluta, mas também a relativa. Considerando-se, no denominador, a População em Idade Ativa (PIA), já que são analisados apenas os movimentos pendulares por motivo trabalho, a pendularidade entre os municípios da OMPETRO evoluiu de 1,32\% para 3,13\% no período supracitado.

Esses resultados atestam um processo incipiente de "complexificação da rede urbana” (OJIMA; MARANDOLA JR., 2012) no Norte Fluminense, a exemplo do que vem ocorrendo no restante do país e, mais especificamente, em outras regiôes do próprio Rio de Janeiro, como argumenta Baeninger (2003) - autora que reconhece um processo de aglomeração urbana no estado fluminense, em Barra Mansa/Volta Redonda e Cabo Frio, e a intensificação da interiorização em direção a Macaé, Campos dos Goytacazes, Nova Friburgo, Petrópolis e Teresópolis. Ademais, os índices refletem uma articulação crescente entre os municípios, desde a Baixada Litorânea até o Norte Fluminense, decorrente, por um lado, da "desconcentraçáo concentrada" da atividade produtiva nessa direção e, por outro, do desenvolvimento dos meios de comunicação e transporte. Eles reforçam, igualmente, a ideia de que a pendularidade tornou-se, em certa medida, um estilo de vida (MOURA; BRANCO; FIRKOWSKI, 2005), na medida em que, para um número cada vez maior de pessoas, inclusive em áreas náo metropolitanas, o local de trabalho vem sendo dissociado do de residência. Os resultados sugerem, por fim, que a desconcentração da pendularidade para o interior tende 
a ganhar notoriedade cada vez mais, tornando, por consequência, "mais complexa a análise das configuraçóes urbano-regionais com características diferentes daquelas encontradas nas metrópoles" (OJIMA et al., 2010). Na esteira dessa discussão, Marandola Jr. e Ojima (2014, p. 186) pontuam que as "recentes alteraçóes na pendularidade estão intimamente ligadas às transformações na vida urbana e nas instituiçóes, numa regionalização do cotidiano, que acompanha a dispersão de atividades industriais, de lazer, de comércio e de empreendimentos imobiliários".

Com base nos municípios selecionados, estimaram-se os fluxos pendulares interestaduais e intraestaduais, incluindo a pendularidade entre eles. É imprescindível elucidar que se optou pelo o conceito mais amplo de pendularidade, implícito nos Censos Demográficos do IBGE, apesar de o Censo de 2010 possibilitar a análise da pendularidade em seu sentido mais estrito. Amplamente, admite-se como pendular o deslocamento que "uma pessoa realiza entre seus locais de residência e de trabalho/estudo, quando estes se localizam em municípios distintos" (PEREIRA; HERRERO, 2009, p. 9 apud SOUZA; TERRA; CAMPOS, 2013, p. 8); já estritamente, tal deslocamento refere-se "[à]quele realizado por indivíduos que trabalham em municípios diferentes do de residência, e que retornam para casa diariamente, independentemente do tempo habitualmente gasto nesse deslocamento" (SOUZA; TERRA; CAMPOS, 2013, p. 8).

Tendo em vista o objetivo deste artigo, não se restringiu a análise à pendularidade daqueles que retornam diariamente para casa, dado o regime de contratação em turnos de um número significativo de trabalhadores no segmento upstream da indústria do petróleo. Cumpre frisar, ainda, que foi avaliada apenas a pendularidade por motivo trabalho.

Concernente à pendularidade interestadual, averígua-se a entrada de 12.329 trabalhadores (Tabela 7), sendo $7.486(60,75 \%)$ originários de estados da própria Regiāo Sudeste, notadamente do Espírito Santo e Minas Gerais. Por se tratar de fluxos pendulares que não envolvem mudança de residência entre a origem e o destino, a alta participação relativa de nordestinos no fluxo (29,72\%) náo surpreende, pois não se trata de movimentos cotidianos. Essa pendularidade de longa distância é possibilitada, por um lado, pelas características do mercado de trabalho da regiáo e, por outro, pelo desenvolvimento do setor de transportes e comunicação.

A saída de trabalhadores pendulares dessa região para outros estados brasileiros é pequena e prevalecem como destino aqueles espacialmente mais próximos. Com exceção de Arraial do Cabo, Carapebus, Casimiro de Abreu e Quissamã, em todos os outros municípios o saldo pendular interestadual é positivo, sendo relativamente mais elevado em Macaé, que recebe praticamente 75\% dos trabalhadores pendulares interestaduais, e em Campos dos Goytacazes.

Os fluxos intraestaduais são significativamente mais densos: a pendularidade bruta, em 2010, foi da ordem de 136.155 trabalhadores. De acordo com a Tabela 6, apenas Macaé e Armação dos Búzios se destacam como áreas de atração intraestadual, tendo o primeiro atraído, em termos líquidos, 41.050 trabalhadores e o segundo, 6.482. Nos demais municípios, o saldo pendular é negativo, o que reflete a baixa capacidade de absorção/retenção da mão de obra residente por seus respectivos mercados de trabalho. 
Tabela 6: Municípios Selecionados - Indicadores da Mobilidade Pendular Interestadual, Intraestadual e Total, segundo o município selecionado, 2010

\begin{tabular}{l|r|r|r|r|r|r|r|r|r}
\hline \multirow{2}{*}{ Municípios Selecionados } & \multicolumn{3}{|c|}{$\begin{array}{c}\text { Pendularidade } \\
\text { Interestadual }\end{array}$} & \multicolumn{2}{c|}{$\begin{array}{c}\text { Pendularidade } \\
\text { Intraestadual }\end{array}$} & \multicolumn{2}{c}{ Pendularidade Total } \\
\cline { 2 - 12 } & Entradas & Saídas & Saldo & Entradas & Saídas & Saldo & Entradas & Saídas & Saldo \\
\hline Armação de Búzios & 128 & 0 & 128 & 6.995 & 513 & 6.482 & 7.123 & 513 & 6.610 \\
\hline Arraial do Cabo & 2 & 29 & -27 & 971 & 2.197 & -1.226 & 973 & 2.226 & -1.253 \\
\hline Cabo Frio & 548 & 340 & 208 & 13.364 & 14.201 & -837 & 13.913 & 14.541 & -628 \\
\hline Carapebus & 6 & 31 & -25 & 275 & 2.417 & -2.142 & 281 & 2.448 & -2.167 \\
\hline Campos dos Goytacazes & 1.994 & 818 & 1.176 & 7.618 & 10.880 & -3.262 & 9.613 & 11.698 & -2.085 \\
\hline Casimiro de Abreu & 20 & 71 & -51 & 2.192 & 4.703 & -2.511 & 2.212 & 4.774 & -2.562 \\
\hline Macaé & 9.190 & 395 & 8.795 & 42.809 & 1.759 & 41.050 & 51.999 & 2.154 & 49.845 \\
\hline Quissamá & 25 & 32 & -7 & 645 & 1.270 & -625 & 670 & 1.302 & -632 \\
\hline Rio das Ostras & 322 & 270 & 52 & 6.064 & 14.210 & -8.146 & 6.386 & 14.480 & -8.094 \\
\hline Sáo Joáo da Barra & 92 & 34 & 58 & 1.492 & 1.580 & -88 & 1.584 & 1.614 & -30 \\
\hline Total & 12.329 & 2.020 & 10.309 & 82.425 & 53.730 & 28.695 & 94.754 & 55.750 & 39.004 \\
\hline Fonte: & & & & & &
\end{tabular}

Fonte: IBGE - Censo Demográfico de 2010.

Em termos consolidados, os saldos pendulares positivos também só se verificaram nesses dois municípios. Do total de trabalhadores pendulares, praticamente $55 \%$ eram absorvidos pelo mercado de trabalho de Macaé; $14 \%$, por Cabo Frio; e 10\%, por Campos dos Goytacazes. Sublinhe-se que, do total de trabalhadores que saíram desses municípios para trabalhar em outro, 26,08\% originaram-se de Cabo Frio, 25,97\%, de Rio das Ostras, e 21\%, de Campos dos Goytacazes.

Esses resultados indicam que tanto Macaé quanto Búzios, apesar das diferentes escalas, além de atraírem muitos trabalhadores residentes em outros municípios, têm uma grande capacidade de retenção da mão de obra lá residente. Isso porque, para cada trabalhador que saiu, entraram 24 em Macaé e 14 em Búzios. Diferentemente, em Cabo Frio, Campos e Rio das Ostras, tanto as entradas quanto as saídas são significativas, sugerindo haver uma seletividade da mão de obra nesses mercados de trabalho, que merece ser melhor compreendida.

Em Macaé, os números da pendularidade indicam uma polarização regional. Esse município se destaca por atrair significativos fluxos não apenas de seus vizinhos, como também de outras UFs, incluindo aquelas mais distantes, como as das regiôes Norte e Nordeste. Apesar de Campos dos Goytacazes ser maior e apresentar uma economia mais diversificada, é Macaé que exerce uma importante centralidade: é em torno dele que se (re)organiza o tecido urbano regional.

Deve-se considerar que Macaé é aquele que possui a planta industrial mais desenvolvida, sediando a base da indústria da exploraçáo e produção de petróleo e gás. Esse fato explica a forte atração que ele exerce não apenas sobre os trabalhadores migrantes, mas também sobre os pendulares.

É interessante notar que, na regiāo em estudo, verifica-se uma urbanização dispersa, diferentemente do caso das Regióes Metropolitanas, cuja expansão horizontal caracteriza-se pela ampliação da já consolidada mancha urbana (OJIMA; MARANDOLA JR., 2012). O único processo incipiente de conurbaçáo verificado encontra-se entre Macaé e Rio das Ostras, município que vem oferecendo incentivos 
fiscais para a instalação de empresas em sua “Zona Especial de Negócios”, estrategicamente localizada na divisa entre os dois municípios.

Com a mensuração dos movimentos migratórios de data fixa e dos movimentos pendulares entre 2005-2010, demonstrou-se a capacidade de atração de mão de obra que os municípios analisados exercem sobre indivíduos que residem em outras regióes do país e em outros municípios do Rio de Janeiro. A partir disso, surge uma outra questão a ser respondida: em que medida os mercados de trabalho desses municípios dependem de mão de obra exógena?

\section{METODOLOGIA PARA A ESTIMATIVA DO NÍVEL DE DEPENDÊNCIA DE MÃO DE OBRA EXÓGENA}

Segundo Januzzi (2005, p. 15), um indicador social é "uma medida em geral quantitativa dotada de significado social substantivo, usada para substituir, quantificar ou operacionalizar um conceito social abstrato", sendo, pois, imprescindível para fins de formulação e monitoramento de políticas públicas.

Como o principal objetivo deste estudo é desenvolver um indicador do nível de dependência de um mercado de trabalho de mão de obra exógena, é necessário formular, claramente, sua conceituação, a partir dos elementos que o compóem.

Em sentido mais amplo, definiu-se como exógena toda a mão de obra ocupada não originária do município, conceito que abrange imigrantes e pendulares. Em relação aos imigrantes, é fato que o verdadeiro motivo que leva aos movimentos migratórios é desconhecido. Mas o predomínio do motivo econômico como seu principal propulsor é muito bem discutido por Ravenstein (1980) e Everett Lee (1980). Além disso, cumpre salientar que, seguindo Singer (1980), as migrações internas são mais do que influenciadas, são "condicionadas" pelo processo de industrializaçáo, sendo que

[...] não parecem ser mais que um mero mecanismo de redistribuiçáo da populaçáo que se adapta, em última análise, ao rearranjo espacial das atividades econômicas. Os mecanismos de mercado que, no capitalismo, orientam os fluxos de investimento às cidades e ao mesmo tempo criam os incentivos econômicos às migraçóes do campo à cidade, não fariam mais que exprimir a racionalidade macroeconômica do progresso técnico que constituiria a essência da industrialização. Tal interpretaçáo faria derivar o processo migratório da própria industrializaçâo (SINGER, 1976 [1980], p. 219).

Para efeitos da elaboração do indicador, considerou-se apenas a População Economicamente Ativa ocupada e, nesse contexto, a informação sobre o motivo que gerou o movimento migratório é de importância secundária. Importa, sim, que o indivíduo seja imigrante e esteja trabalhando na data de referência do Censo Demográfico. Admitindo-se que os migrantes antigos já passaram por um processo de seletividade - tendo sobrevivido à mortalidade e à reemigração apenas aqueles que conseguiram adaptar-se à sociedade receptora, inserir-se no mercado de trabalho (formal ou informal) e incorporar-se à dinâmica socioeconômica da região de destino -, optou-se por considerar como mão de obra exógena somente os migrantes mais recentes, captados pelo quesito data fixa. É importante elucidar, ainda, que 
o indivíduo que nasceu no município, emigrou e retornou é incorporado àqueles que nasceram e nunca residiram em outro lugar; pressupóe-se que sua emigração serviu como um investimento em capital humano para favorecer sua (re)inserção no mercado de trabalho de origem. Em outras palavras, o imigrante natural de retorno náo é considerado mão de obra exógena, ainda que ele possa ter retornado pelo maior dinamismo econômico do município.

No que se concerne aos movimentos pendulares, foi adotado seu conceito mais abrangente, cuja estimativa é feita pelo cruzamento entre as informações do município de residência e do município onde o indivíduo trabalha. Sendo assim, todo indivíduo que declarou como local de trabalho um município diferente do de residência foi considerado trabalhador pendular, independentemente da distância e da periodicidade do deslocamento. Isso foi feito porque não há necessidade de separar os pendulares que retornam diariamente para casa daqueles que permanecem por mais tempo no local de trabalho, tendo em vista as contrataçóes por regimes de turnos.

Em determinados contextos, como no caso das Regiōes Metropolitanas, talvez seja mais adequado adotar um conceito estrito para a definição de mão de obra exógena, que se restringiria aos trabalhadores pendulares.

Vencido o desafio da definição do numerador, entende-se como denominador do indicador aqui proposto a população ocupada $\underline{\text { NO }}$ município e não a população ocupada RESIDENTE no município. A primeira é composta por indivíduos que trabalham no próprio município de residência e também por indivíduos que, apesar de residirem em outra cidade, o declaram como local de trabalho. Já a segunda engloba todos aqueles que lá residem e trabalham, assim como todos aqueles que lá residem, mas que podem trabalhar em outra cidade.

Para a identificação do denominador, utilizaram-se os seguintes critérios:

1. População ocupada que trabalha no próprio município de residência: Essa parcela do denominador é facilmente identificável através do cruzamento das informaçóes referentes à condição de ocupação na semana de referência, tendo sido selecionados apenas os ocupados no município de residência e no município onde trabalhava em 2010;

2. População ocupada residente em outro município, mas que trabalhava em algum dos municípios selecionados: Dada a especificidade do regime de contratação em turnos de um número significativo de trabalhadores no segmento upstream da indústria do petróleo, para se chegar a essa parcela do denominador, julgou-se necessário verificar, em cada um dos municípios do Rio de Janeiro e nas demais Unidades da Federação, a população residente ocupada que declarou, como local de trabalho, algum dos municípios selecionados.

Sendo assim, o nível de dependência de um mercado por mão de obra exógena - amplo ou estrito - é dado pela fórmula (1):

$$
N d=\frac{M D O_{\text {exogena }}}{M D O_{\text {ocupada }}} * 100
$$

Onde:

- $\quad \mathrm{Nd}$ = nível de dependência de mão de obra exógena;

- MDOexógena (indicador amplo) = imigrante náo natural entre duas datas fixas que declarou trabalhar no município de residência + indivíduo não residente que declarou trabalhar no município (pendular); 
- MDOexógena (indicador estrito) = indivíduo não residente que declarou trabalhar no município (trabalhador pendular);

- $\quad$ MDOocupada = indivíduo natural que reside e trabalha no município + indivíduo não natural residente no município, mas que o declarou como local de trabalho + indivíduo não residente que declarou trabalhar no município.

Esse indicador adota uma metodologia similar àquela do nível de dependência dos municípios em relação aos royalties e participaçóes especiais, que tem como numerador as rendas petrolíferas (royalties e participaçóes especiais) e, como denominador, a Receita Orçamentária Total - esta, por sua vez, inclui as rendas petrolíferas. Tal indicador é amplamente utilizado na literatura econômica que trata dos impactos das atividades de produção de petróleo e gás nos municípios produtores de petróleo. Os trabalhadores pendulares entram tanto no numerador quanto no denominador, uma vez que se definiu, como denominador, a população ocupada NO município e não a população ocupada RESIDENTE no município, cujas diferenças conceituais foram anteriormente apontadas.

Antes de serem calculados os níveis de dependência para os municípios selecionados, são estimados o quociente entre a PEA ocupada no município e a PEA ocupada residente no município, pela fórmula (2):

$$
C_{a b}=\left\{\left[\frac{P E A_{\text {ocupada }}}{P E A_{\text {ocupadaressidente }}}\right]-1\right\} * 100
$$

\section{ANÁlisE DOS RESULTADOS}

De acordo com o Censo Demográfico de 2000, o conjunto de municípios selecionados contava com uma população de 817.131 habitantes. Entre 2000 e 2010, a população residente cresceu num ritmo médio anual de $3,2 \%$, enquanto a população fluminense cresceu, em sua totalidade, $1,06 \%$ ao ano.

No caso examinado, havia, em 2010, uma População Economicamente Ativa ocupada residente de 497.585 trabalhadores (formais e informais). Na Tabela 8, é possível observar a composição dessa PEA, segundo a localidade onde trabalha.

A relação entre a PEA ocupada residente que trabalha no próprio município e o total da PEA ocupada residente pode ser compreendida como um indicador da capacidade de retenção de mão de obra. Apenas três municípios se destacam pela alta capacidade de retenção de sua mão de obra residente (seja ela natural, seja náo natural): Macaé (97,41\%); Armação dos Búzios (95,90\%); e Campos dos Goytacazes (93,07\%). Nos demais, a capacidade de retenção apresenta-se relativamente mais baixa, sendo significativas as parcelas de máo de obra ocupada absorvidas por outros mercados de trabalho. Para Carapebus, Rio das Ostras e Casimiro de Abreu, esses percentuais são, respectivamente, 40,74\%, 29,66\% e 28,83\%. Essa baixa retenção pode estar associada à escassez de postos de trabalho e/ou à não adequaçáo entre a qualificação do trabalhador e aquela exigida pelos postos de trabalho disponíveis.

Assinale-se que esse indicador - isto é, o percentual de trabalhadores pendulares em relação à PEA total - é bastante utilizado para se analisar as "cidades-dormitórios"; nesse sentido, o elevado percentual de trabalhadores pendulares dos municípios citados acima sugere que eles podem vir a se tornar, em um futuro próximo, cidades- 
dormitórios. Muito embora Cunha (2006 apud OJIMA et al., 2010) aponte para o surgimento de um novo padrão de cidades-dormitórios, na maioria das vezes esse termo vincula-se "aos processos de marginalização e periferização da pobreza [...] e a algumas características, como baixo dinamismo econômico, elevado crescimento populacional e expansão urbana em assentamentos precários de populaçáo de baixa renda" (OJIMA et al., 2010, p. 396, 398).

Tabela 7: Municípios selecionados - PEA residente, segundo o local de trabalho, 2010

\begin{tabular}{l|r|r|r|r|r|r}
\hline \multirow{2}{*}{ Municípios Selecionados } & \multicolumn{5}{|c}{ PEA ocupada RESIDENTE no município } \\
\cline { 2 - 8 } & \multicolumn{2}{|c|}{$\begin{array}{c}\text { Trabalha no próprio } \\
\text { município }\end{array}$} & \multicolumn{2}{c}{$\begin{array}{c}\text { Trabalha em outro } \\
\text { município ou país } \\
\text { estrangeiro }\end{array}$} & \multicolumn{2}{c}{ PEA residente total } \\
\cline { 2 - 8 } & Absoluto & \multicolumn{1}{c}{$\%$} & Absoluto & \multicolumn{1}{c}{$\%$} & \multicolumn{1}{c}{ Absoluto } & \multicolumn{1}{c}{$\%$} \\
\hline Armação de Búzios & 13.039 & 95,90 & 557 & 4,10 & 13.596 & 100,00 \\
\hline Arraial do Cabo & 10.249 & 81,52 & 2.324 & 18,48 & 12.573 & 100,00 \\
\hline Cabo Frio & 69.346 & 81,78 & 15.445 & 18,22 & 84.791 & 100,00 \\
\hline Carapebus & 3.604 & 59,26 & 2.478 & 40,74 & 6.082 & 100,00 \\
\hline Campos dos Goytacazes & 173.998 & 93,07 & 12.958 & 6,93 & 186.956 & 100,00 \\
\hline Casimiro de Abreu & 12.266 & 71,17 & 4.970 & 28,83 & 17.236 & 100,00 \\
\hline Macaé & 100.154 & 97,41 & 2.658 & 2,59 & 102.812 & 100,00 \\
\hline Quissamã & 7.198 & 83,48 & 1.424 & 16,52 & 8.622 & 100,00 \\
\hline Rio das Ostras & 35.519 & 70,34 & 14.974 & 29,66 & 50.493 & 100,00 \\
\hline São João da Barra & 12.724 & 88,21 & 1.700 & 11,79 & 14.424 & 100,00 \\
\hline Total & 438.097 & 88,04 & 59.488 & 11,96 & 497.585 & 100,00 \\
\hline
\end{tabular}

Fonte: IBGE - Censo Demográfico de 2010.

A Tabela 9 mostra que a PEA ocupada é bem maior do que a PEA ocupada residente. Aplicando-se a metodologia descrita na seção 6, específica para a identificação da populaçáo ocupada que trabalha no município, estima-se um total de 532.851 indivíduos que trabalham em algum dos municípios selecionados.

No entanto, apenas em Armação dos Búzios e em Macaé, a PEA ocupada no município é, de fato, superior à residente. Isso significa que, mesmo se toda a população ocupada residente nesses municípios fosse completamente absorvida pelos respectivos mercados de trabalho, ainda assim faltariam trabalhadores para ocuparem todos os postos de trabalho existentes. Em Armação de Búzios, a população ocupada é 48,31\% maior que a ocupada residente; já em Macaé esse percentual é de 47,99\%. Provavelmente, no período censitário, havia indivíduos residentes desempregados nesses municípios, o que não é um paradoxo. Souza, Terra e Campos (2012) chamam a atenção para a o baixo nível de escolaridade dos naturais dos municípios da OMPETRO, inferindo que a baixa qualificação profissional dos indivíduos funciona como uma barreira à (re)inserção deles nesse mercado de trabalho, extremamente intensivo em capital.

Nos demais municípios, pode-se afirmar que o mercado de trabalho não consegue absorver toda a populaçáo ocupada residente, seja por escassez de postos de trabalho, seja pela baixa qualificação profissional da PEA, havendo necessidade de sua "exportação" para outras cidades. Ressalte-se, ainda, que as diferenças entre os rendimentos médios dos trabalhadores entre os municípios selecionados funcionam como um importante fator de estímulo à realização da pendularidade. 
TABELA 8: Municípios Selecionados - Relação entre as PEA ocupada no município e a PEA ocupada residente no município, por município selecionado, 2010

\begin{tabular}{l|r|r|r}
\hline Município Selecionado & \multicolumn{1}{|c|}{$\begin{array}{c}\text { PEA ocupada que } \\
\text { trabalha NO } \\
\text { município (1) }\end{array}$} & $\begin{array}{c}\text { PEA ocupada } \\
\text { RESIDENTE no } \\
\text { município (2) }\end{array}$ & $\begin{array}{c}\text { Relação entre as PEA's } \\
(1) /(2)\end{array}$ \\
\hline Armaçáo dos Búzios & 20.164 & 13.596 & $-10,73$ \\
\hline Arraial do Cabo & 11.224 & 12.573 & $-1,81$ \\
\hline Cabo Frio & 83.256 & 84.792 & $-36,11$ \\
\hline Carapebus & 3.885 & 6.081 & $-1,79$ \\
\hline Campos dos Goytacazes & 183.610 & 186.957 & $-16,00$ \\
\hline Casimiro de Abreu & 14.479 & 17.236 & 47,99 \\
\hline Macaé & 152.153 & 102.811 & $-8,74$ \\
\hline Quissamá & 7.868 & 8.621 & $-17,00$ \\
\hline Rio das Ostras & 41.907 & 50.493 & $-0,80$ \\
\hline São Joáo da Barra & 14.308 & 14.424 & 7,09 \\
\hline Territórios & 532.851 & 497.584 & \\
\hline Fonte: IBGE & & &
\end{tabular}

Fonte: IBGE - Censo Demográfico de 2010.

A Tabela 9 traz os níveis de dependência de mão de obra exógena - ampliado e estrito. Em um mercado de trabalho autossuficiente, ou seja, completamente independente de mão de obra exógena, o nível de dependência seria nulo; para aquele que fosse completamente dependente de mão de obra exógena, o nível de dependência seria de $100 \%$. Se, por um lado, dificilmente encontram-se mercados de trabalho com tais características, por outro, tais valores servem de referência para a análise do grau de dependência de um mercado de trabalho. Sendo assim, quanto mais próximo de 0 , menor o nível de dependência; quanto mais próximo de 100, maior ele será.

Como se observa, o nível de dependência ampliado é relativamente alto em todos os municípios. Em apenas quatro deles - Quissamã, Campos dos Goytacazes, Arraial do Cabo e Casimiro de Abreu -, o indicador é inferior a 40\%, ou seja, menos de $40 \%$ da mão de obra ocupada no município é migrante recente (de data fixa) ou trabalhador pendular. Armação de Búzios e Macaé apresentaram um índice superior a 50\%, mostrando, assim, um nível extremamente alto de dependência de mão de obra exógena: $55,38 \% 59,69 \%$, respectivamente.

Já em relação ao indicador mais estrito, que restringe o numerador aos movimentos pendulares, Búzios e Macaé permanecem com os índices mais elevados: 35,34\% e $34,18 \%$, nessa ordem. Essa diferença entre o indicador ampliado e estrito deve-se aos movimentos migratórios. Pode-se dizer que, para Búzios e Macaé, os dois componentes desse indicador - migração e pendularidade - têm praticamente a mesma importância no suprimento de mão de obra (mais qualificada) para o mercado de trabalho aí existente. Dentre os trabalhadores exógenos, em Macaé, 57,3\% são pendulares (intra e interestaduais); em Búzios, o percentual atinge 63,8\%. Já para Campos, onde apenas $5 \%$ da mão de obra ocupada no município é pendular, há um peso relativamente alto das migraçôes na composição do seu nível de dependência. Em tal município, no grupo de trabalhadores exógenos, $82,7 \%$ são imigrantes (não naturais e de data fixa). 
Tabela 9: Municípios selecionados - População, Nível de Dependência das Rendas Petrolíferas e Nível de Dependência de Mão de Obra exógena, 2010

\begin{tabular}{l|r|r|r|r}
\hline \multirow{2}{*}{ Municípios Selecionados } & \multirow{2}{*}{ População } & \multicolumn{3}{|c}{ Nível de Dependência } \\
\cline { 3 - 6 } & & $\begin{array}{c}\text { das Rendas } \\
\text { Petrolíferas }\end{array}$ & $\begin{array}{c}\text { de Mão de Obra } \\
\text { (indicador Ampliado) }\end{array}$ & $\begin{array}{c}\text { de Mão de Obra } \\
\text { (indicador Estrito) }\end{array}$ \\
\hline Armaçáo dos Búzios & 27.560 & 39,1 & 55,38 & 35,34 \\
\hline Arraial do Cabo & 27.715 & 9,4 & 34,73 & 8,69 \\
\hline Cabo Frio & 186.227 & 36,4 & 40,98 & 16,71 \\
\hline Campos dos Goytacazes & 463.731 & 59,4 & 30,27 & 5,24 \\
\hline Carapebus & 13.359 & 45,0 & 47,11 & 7,24 \\
\hline Casimiro de Abreu & 35.347 & 41,8 & 38,35 & 15,28 \\
\hline Macaé & 206.728 & 33,7 & 59,69 & 34,18 \\
\hline Quissamã & 20.242 & 48,5 & 36,41 & 8,51 \\
\hline Rio das Ostras & 105.676 & 59,9 & 46,14 & 15,24 \\
\hline São João da Barra & 32.747 & 74,3 & 42,40 & 11,07 \\
\hline
\end{tabular}

Fonte: IBGE - Censo Demográfico de 2010.

\section{CONSIDERAÇÕES FINAIS}

Náo resta dúvida de que a exploração de petróleo e gás na Bacia de Campos gerou, nos casos aqui analisados, significativas mudanças demográficas e socioeconômicas, decorrentes dos crescentes investimentos relacionados nas atividades petrolífera e parapetrolífera. Essa dinâmica produziu novas oportunidades no mercado de trabalho da regiáo, atraindo, como indicam os resultados dos movimentos migratórios do Censo de 2010, um número relativamente alto de migrantes, o que, consequentemente, elevou a taxa de crescimento populacional dos municípios selecionados acima da média estadual. A única exceção é Campos dos Goytacazes, que apresentou saldo migratório negativo, da ordem de 7 mil pessoas.

Em decorrência do dinamismo econômico, percebe-se, segundo Souza, Terra e Campos (2013), um incremento dos movimentos pendulares entre os municípios da OMPETRO entre 2000 e 2010. Em 2010, a pendularidade total foi da ordem de 94.754 trabalhadores, incluindo os movimentos pendulares interestaduais, intraestaduais e inter-regionais.

Com base no que foi investigado, apenas Macaé e Armação de Búzios apresentam saldo pendular positivo. Macaé, por concentrar as atividades - diretas e indiretas - da indústria petróleo e gás, e Búzios, pelo desenvolvimento do setor de turismo. Os resultados apontam, ainda, uma possível transformação de Casimiro de Abreu, Rio das Ostras e Carapebus, todos nas proximidades de Macaé, em cidades-dormitórios. Macaé, por sua vez, tem ganhado destaque como uma centralidade urbana, apesar da histórica centralidade de Campos dos Goytacazes. Isso sugere, dentre outras coisas, que certos processos, antes restritos ao contexto metropolitano, estão extravazando os limites da metrópole e alcançado áreas interioranas.

A construção de uma metodologia para a estimativa do nível de dependência de mão de obra exógena em um mercado de trabalho é a principal 
contribuição deste artigo, porquanto se trata de um novo indicador. Foram estimados dois indicadores de dependência, a partir de dois conceitos de mão de obra exógena: o primeiro ampliado, estando nele incluídos os trabalhadores imigrantes (não naturais e de data fixa) e pendulares, e outro estrito, com apenas os trabalhadores pendulares.

Os resultados obtidos apontam para uma significativa dependência de mão de obra exógena. O nível de dependência ampliado apresentou-se alto em todos os municípios, tendo superado os 50\% em Macaé (59,69\%) e Búzios (55,38\%). Referente ao indicador mais estrito, Búzios e Macaé permanecem com os índices mais elevados, $35,34 \%$ e $34,18 \%$, respectivamente. A diferença entre o indicador ampliado e estrito deve-se aos movimentos migratórios.

O estudo abre portas para pesquisas que poderão ser desenvolvidas no intuito de conhecer o perfil da mão de obra exógena que esse conjunto de municípios depende. Há uma clara seletividade no mercado de trabalho examinado. Qual o nível de qualificação e remuneração médios? Há diferenças significativas entre os perfis da mão de obra exógena entre os municípios?

\section{REFERÊNCIAS}

BAENINGER, R. A. Cidades e Metrópoles: a desaceleração no crescimento populacional e novos arranjos regionais. In: CONGRESSO BRASILEIRO DE SOCIOLOGIA, 11., 2003, Campinas. Anais do XI Congresso Brasileiro de Sociologia. Campinas: SBS, 2003.

Interiorizaçâo da migração em São Paulo: novas territorialidades e novos desafios teóricos. In: ENCONTRO NACIONAL DE ESTUDOS POPULACIONAIS, 14., 2004, Caxambu. Anais do XIV Encontro Nacional de Estudos Populacionais. Caxambu: ABEP, 2004.

BRITO, F. Brasil, final do século: a transição para um novo padrão migratório. In: CARLEIAL, A (Org.). Transiçōes migratórias. Fortaleza: Iplance, 2002. p. 54-72.

CARVALHO, J. A. M.; RIGOTTI, J. I. R. Os dados censitários brasileiros sobre migraçôes internas: algumas sugestóes para análise. Revista Brasileira de Estudos Populacionais, Brasília, v. 15, n. 2, p. 7-17, 1998.

CUNHA, J. M. P. da. Retratos da Mobilidade Espacial no Brasil: Os Censos Demográficos como fontes de dados. Revista Interdisciplinar da Mobilidade Humana, Brasília, v. XX, n. 39, p. 29-50, jul./dez. 2012.

GOLGHER, A. B. Diagnóstico do processo migratório no Brasil 1: Comparaçấo entre não migrantes e migrantes. Belo Horizonte: CEDEPLAR/UFMG, fev. 2006. (Texto para Discussão, 282).

JANUZZI, P. M. Cinquenta anos de mobilidade social e migração no Brasil. In: Migração e Mobilidade Social: migrantes no mercado de trabalho paulista. Campinas: Autores Associados, 2000. p. 5-37.

Indicadores Sociais no Brasil: conceitos, fontes de dados e aplicações. Campinas: Alínea; PUC-Campinas, 2001. v. 1. 141 p.

Indicadores para Diagnóstico, Monitoramento e Avaliação de Programas Sociais no Brasil. Revista do Serviço Público, Brasília, v. 56, n.2, p. 137-159, 2005.

LEE, E. S. Uma teoria sobre migração. In: MOURA, H. (Coord.). Migração Interna, Textos Selecionados. Fortaleza: BNB; ETENE, 1980.
Joseane de Souza: joseanedesouza.souza@gmail.com.

Denise Cunha Tavares Terra: deniseterra@gmail.com.

Artigo recebido em fevereiro de 2015 e aprovado para publicação em abril de 2015. 
MARANDOLA, JR., E; OJIMA, R. Pendularidade e vulnerabilidade na Região Metropolitana de Campinas: repercussóes na estrutura e no habitar urbano. Revista Brasileira de Estudos Urbanos e Regionais, v.16, n. 2, p.185-203, nov. 2014.

MEDEIROS JÚNIOR, H. Dinâmica populacional e econômica regional, e o mercado de trabalho fluminense entre 2000 e 2010. In: ENCONTRO NACIONAL DA ANPUR, 15., 2013, Recife. Anais do XV Encontro da ANPUR. Recife: ANPUR, 2013.

MIRANDA LEMOS, L.; BARRAL NETTO, J. F. As implicaçôes em se pensar na constituição de uma região no interior do estado do Rio de Janeiro a partir do petróleo. In: SANTOS, A. M. P.; MARAFON, G. J.; SANT’ANNA, M. J. G. (Org.). Rio de Janeiro. Um olhar socioespacial. Rio de Janeiro: Gramma, 2010. p. 279-297.

MONIÉ, F. Petróleo, industrialização e organização do espaço regional. In: PIQUET, R. (Org.). Petróleo, royalties e região. Rio de Janeiro: Garamond, 2003. p. 257-285.

MOURA, R.; CASTELLO BRANCO, M. L. G; FIRKOWSKI, O. L. C. F. Movimento pendular e perspectivas de pesquisas em aglomerados urbanos. São Paulo em Perspectiva, São Paulo, v. 19, n. 4, p.121-133, out./dez. 2005.

OJIMA, R.; MARANDOLA JR., E. Mobilidade populacional e um novo significado para as cidades: dispersão urbana e reflexiva na dinâmica regional não metropolitana. Revista Brasileira de Estudos Urbanos e Regionais, Rio de Janeiro, v. 14, n. 2, p. 103-116, nov. 2012.

OJIMA, R. et al. O estigma de morar longe da cidade: repensando o consenso sobre as cidades-dormitório. Cadernos Metrópole, São Paulo, v. 12, n. 24, p. 395-415, jul./dez. 2010.

OLIVEIRA, A. T. R. Algumas abordagens teóricas a respeito do fenômeno migratório. In: OLIVEIRA, L. A. P.; OlIVEIRA, A. T. R. (Org.). Reflexóes sobre os deslocamentos populacionais no Brasil. Rio de Janeiro: IBGE, 2011. v. 1. p. 11-28.

PERSPECTIVAS de investimento na indústria: 2012-2015. Visāo de Desenvolvimento BNDES, Brasília, n. 100, p. 1-7, 19 abr. 2012.

RAVENSTEIN, E. G. As Leis da Migração. In: MOURA, H. (Coord.). Migração Interna, Textos Selecionados. Fortaleza: BNB; ETENE, 1980.

SIMÓES, R.; AMARAL, P. Interiorização e novas centralidades urbanas: uma visão prospectiva para o Brasil. Economia, Brasília, v. 12, n. 3, p. 553-579, set./dez. 2011.

SINGER, P. Economia Política e urbanização. In: MOURA, H. (Coord.). Migração Interna, Textos Selecionados. Fortaleza: BNB; ETENE, 1980.

SOUZA, J.; TERRA, D. C. T.; CAMPOS, M. M. O migrante na reestruturaçâo do mercado de trabalho na zona da produçáo principal da Bacia de Campos. In: ENCONTRO NACIONAL DE ESTUDOS POPULACIONAIS, 18., 2012, Águas de Lindóia. Anais do Encontro Nacional de Estudos Populacionais. São Paulo: ABEP, 2012.

; ______________. A mobilidade pendular entre os municípios da Ompetro-RJ (2000 - 2010). In: ENCONTRO NACIONAL DA ANPUR, 15., 2013, Recife. Anais do XV Encontro da ANPUR. Recife: ANPUR, 2013.

TERRA, D. A formação de um cluster petrolífero nos municípios da Bacia de Campos. In: PIQUET, R. (Org.), Petróleo, royalties e regiāo. Rio de Janeiro: Garamond, 2003. p. 287-305.

A B S T R A C T : Producers municipalities of oil in the Bacia de Campos, state of Rio de Janeiro, have shown significant economic and social transformations. There is a change in the occupational structure, driven by new work opportunities in the secondary and tertiary sectors, which has attracted many immigrants, besides the growth of swinging for work reason. This article aims to understand this new dynamic and, therefore, developed an indicator to measure the level of dependency of a hand work of exogenous labor 
JOSEANE DE SOUZA, DENISE CUNHA TAVARES TERRA

market, assumed to be composed of all the immigrant workers (unnatural and date-fixed), living in certain municipality, and also for commuters. The results show that the hand level of dependency of exogenous work of these municipalities can reach up to about 60\%, as is the case of the city of Macaé, which is the Petrobras's base of operations as well of others oil companies settled there.

K E Y W O R D S : level of dependence; migration; pendularity, labour market. 